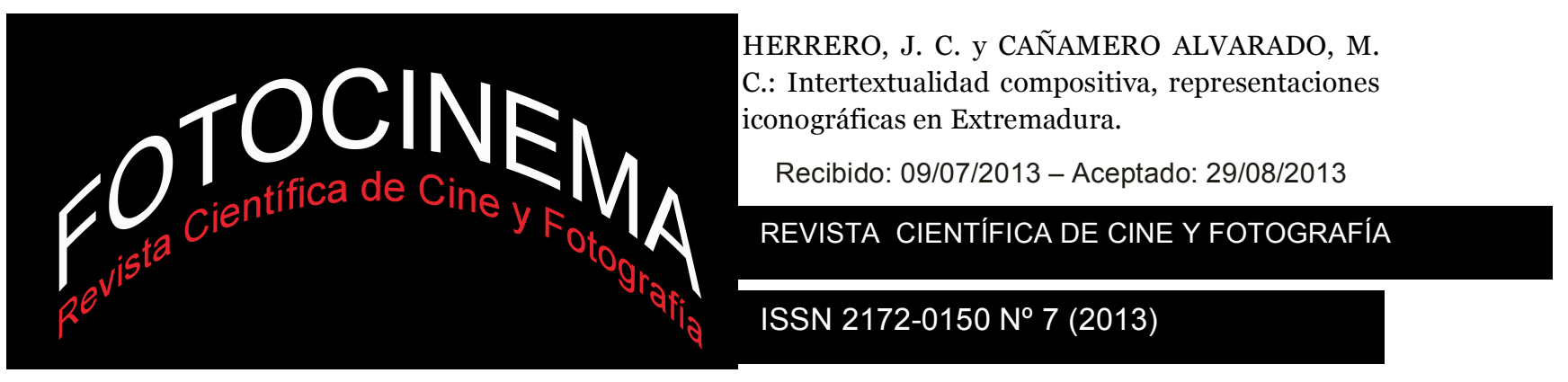

\title{
INTERTEXTUALIDAD COMPOSITIVA, REPRESENTACIONES ICONOGRÁFICAS EN EXTREMADURA
}

\section{INTERTEXTUALITY COMPOSITIONAL ICONOGRAPHIC REPRESENTATIONS IN EXTREMADURA}

\author{
Julio César Herrero \\ Ma Cristina Cañamero Alvarado \\ Universidad Camilo José Cela
}

\section{Resumen:}

Durante la primera mitad del siglo $\mathrm{XX}$, la fotografía y el cine documental tuvieron un gran peso dentro de los medios de comunicación, acercando con sus imágenes los acontecimientos, tipos, formas, cultura... desde cualquier punto de la tierra. Extremadura se convierte en un inusitado objeto de estudio por parte de diferentes autores nacionales e internacionales, como Ruth Matilda Anderson, Luis Buñuel o W. Eugene Smith, erigiéndose en unas décadas como protagonista de la imagen que España proyecta al exterior. Dichos autores trabajarán en diferentes décadas mostrando en sus obras líneas de intertextualidad compositiva, que vendrán dadas por los elementos iconográficos comunes.

Presentamos un análisis de imágenes, en cuatro grupos de muestra: vivienda; infraestructuras; maternidad e infancia. Para poder realizar un estudio de imágenes que diferente procedencia seguiremos una plantilla de análisis para mostrar las semejanzas morfológicas y compositivas.

\begin{abstract}
:
During the first half of the twentieth century, photography and documentary film weighed heavily in the media, with their images approaching events, types, shapes, culture... from anywhere on earth. Extremadura becomes an unusual object of study by different national and international authors like Ruth Matilda Anderson, Luis Buñuel or W. Eugene Smith, standing out in a few decades as the protagonist of the image projected outside Spain. These authors work in different decades showing intertextuality works compositional lines, which are given by the common iconographic elements.

We present an image analysis sample into four groups: housing, infrastructure, motherhood and childhood. In order to perform a study of different backgrounds images that follows a template of analysis, which will guide us in showing the morphological and compositional similarities.
\end{abstract}

Palabras clave: Intertextualidad; Extremadura; imagen; iconográfico.

Keywords: Intertextuality; Extremadura; image; iconography. 


\section{Introducción}

Con el presente trabajo se pretende mostrar las relaciones intertextuales que se crean entre diferentes trabajos fotográficos y cinematográficos de diferentes décadas, pero correlativos en el tiempo y que se desarrollan en un país común, España, poniendo también de manifiesto la relación intertextual que se establece entre trabajos realizados por profesionales de distintas nacionalidades, estadounidenses y españoles.

Se trata de un estudio que abarca aspectos compositivos, morfológicos, estéticos y artísticos de la imagen ${ }^{1}$, sobre el retrato de la visión particular que unos autores ofrecieron al mundo de una zona geográfica concreta, Extremadura, a través de su trayectoria y actividad profesional bien fuera periodística, artística o cinematográfica.

Se aborda el tema recurrente en el mundo de la imagen o de la creación artística, de la composición en sí misma como punto de controversia. Dentro de los estudios de Comunicación Audiovisual y de la Estética, o las Bellas Artes, se ha puesto muchas veces en tela de juicio la originalidad y la naturalidad, o instantaneidad de algunas imágenes, en realidad ha sido una protagonista casi omnipresente en la vida de occidente desde el nacimiento de la primera imagen fija perdurable, la Heliografía.

Uno de los puntos restrictivos, en el estudio que se plantea sobre la intertextualidad compositiva, sería la selección de la obra que aquí se analiza, los autores y sus obras. Son autores genuinos en su género y sus obras, a través de las cuales buscaremos las relaciones comunes que establecen sus lenguajes visuales. Esta premisa, que puede parecer una limitación en un primer momento, es lo que invita a la realización de la investigación así como una necesidad metodológica, la búsqueda de relaciones entre el lenguaje de los autores persigue conocer hasta qué punto querían crear un producto

\footnotetext{
${ }^{1}$ La definición de imagen según la R.A.E.: “3. f. Ópt. Reproducción de la figura de un objeto por la combinación de los rayos de luz que proceden de él", es la que referencia que se utilizará a lo largo del texto para hablar del conjunto de imágenes de estudio, bien sea referido a la fotografía o imagen fija, bien sea a la imagen en movimiento o cinematógrafo, puesto que lo que se estudia es un fotograma, pudiendo ser aplicados los criterios de estudio de una fotografía.
}

242 
visual nuevo, o si lo que mostraron con su obra eran los aspectos intrínsecos de la iconografía occidental presente en las fotografías del género documental o periodístico desde el principio de la presentación de la primera imagen fija en el París en el siglo XIX.

El estudio no sólo aporta una visión particular de autores y época concretos, si no que aplica una metodología aplicable en otros estudios de imagen, examinando si la imagen crea o refleja los estereotipos sociales, y localizar las causas de que dichos estereotipos aparezcan de forma constante en las referencias visuales del siglo XX.

\section{Tiempo, espacio y protagonistas}

Como se ha señalado, son trabajos creativos que contienen representaciones iconográficas fácilmente reconocibles, poses, tipos... que han ocupado los medios audiovisuales en el siglo XX en diversos formatos aunque, por la época en la que fueron publicadas las obras que se van a analizar, lo hicieron en formatos tradicionales: cine, prensa y/o libros. La historia de la fotografía es breve en el momento que los autores analizados realizaron su obra si la comparamos con los medios impresos, pero aún es más breve la historia del cinematógrafo, casi cincuenta años más joven que su predecesora.

La elección de las fotografías y fotogramas para el análisis, así como el corte de la época, obedece a un motivo práctico y de necesidad para poder atenernos a un estudio metodológico que se puede aplicar a los documentos gráficos no manipulados digitalmente, pertenecientes a una era analógica y a un segmento concreto de la historia del siglo XX: su primera mitad, en la que el fotoperiodismo y los documentales antropológicos o sociológicos tenían un gran sentido y cabida en la sociedad, sabiendo que el momento histórico sujeto al estudio fueron los inicios de estas especialidades periodísticas y artísticas. Los autores de referencia fueron protagonistas. Los criterios selectivos de la muestra han sido la coherencia argumental con los estudios etnográficos y geográficos anteriores y posteriores realizados en la zona, como se explicará más adelante en el texto. 
También el marco geográfico del estudio, Extremadura, concretamente Cáceres, que se identifica con tierra de conquistadores. No en vano, es sabido que de allí han salido nombres insignes de la Historia de nuestro país, como Hernán Cortes o Francisco Pizarro. También se identificó con pobres y emigración, en buena medida debido a la imagen que se transmitió de esta provincia y sus gentes en el siglo XX.

En general, la imagen de los que nunca habían pisado tierras extremeñas es de una tierra árida, pobre y abrupta, con gentes cerradas y algo faltas de entendimiento, construida sobre la base de información que se forjó en estas décadas, extrapolando algunos de los aspectos mencionados sobre la comarca de Las Hurdes a las demás comarcas cacereñas. Información que había sido ampliamente difundida mediante las publicaciones de la tesis de Mauricio Legendre y la visita a las Hurdes de Alfonso XIII acompañado del Dr. Gregorio Marañón. Pero la realidad es bien distinta. La riqueza natural, cultural y humana de la región ha sido demostrada a lo largo de las últimas décadas, convirtiéndose en uno de los puntos de referencia del turismo de nuestro país, y máxime con la evolución social y cultural a la que se ha sometido esta tierra.

La imagen, tanto fija como en movimiento, desde su nacimiento y durante su evolución histórica ha pasado por diferentes técnicas que han permitido dejar constancia gráfica de lo acontecido en la Historia de la Humanidad. Recoge el testigo de la pintura como "retratista" del entorno, se asume que el recién nacido invento allá por el 1840, es una fiel reproductora de la realidad, no imita como lo hace la pintura, sino que se convierte en el vehículo transmisor y conservador de un fugaz instante en la vida del hombre.

"Puede que la fotografía se pretenda todavía como documento porque de hecho, toda imagen, incluso la más ambigua o la más abstracta, contiene un cierto magma de información”. (Fontcuberta, 1984, 179)

La época histórica donde contextualizaremos el estudio se centra en tres décadas, con su inicio en los "felices y prósperos años 20" para llevarnos hasta la década de los 50 en nuestro siglo pasado. Concretamente, las 
imágenes analizadas se ubican entre esos años. Dado que los cambios sociales fueron de especial relevancia se ha querido plasmar al completo esta década, ya que estos importantes trasiegos de la sociedad hicieron que fuese una época en la que España se “expuso" al mundo exterior, convirtiéndose en un punto de referencia en el mundo cinematográfico. Por ello España tuvo el apodo de "el gran plató". Impulsado por las necesidades de apoyos externos del régimen de Franco, abriendo zonas geográficas como Almería o Madrid a las grandes superproducciones internacionales.

La prensa a principios del siglo XX se desarrollará de un modo formidable por diversas cuestiones, tales como el avance en los medios de impresión que van incorporando progresivamente la imagen, nuevos medios de comunicación, como el cinematógrafo, junto con el progresivo reconocimiento de la libertad de expresión, lo que fomenta el crecimiento del público receptor (Gutiérrez Espada, 1982).

Es complicado en unos pocos años, borrar la huella de la imagen forjada durante todo un siglo. Reforzada más aún por el hecho de que desde la postguerra hasta los años 60 del siglo XX, las grandes ciudades industriales de España, Francia y Alemania, abrieron sus puertas a una nutrida población de emigrantes extremeños que pasaron del paupérrimo campo a las cadenas de montaje de las fábricas marcadas por la propia evolución industrial que emergía en ese momento histórico. Aunque no es del todo cierto que huyesen del cultivo de sus pequeños minifundios o del trabajo en los latifundios de la aristocracia. Algunos de ellos, se vieron en la obligación de abandonar sus pueblos puesto que habían quedado marcados políticamente habiendo luchado en el bando Republicano durante la Guerra Civil Española. Ello suponía una seña inconfundible que impedía poder desarrollar actividades de cierto tipo, y que hacía que la vida estuviese regida por el temor a las fuerzas del orden bajo un gobierno dictatorial.

La fugacidad del momento es captada, capturada, por las imágenes de prensa o los documentales audiovisuales, que en este instante se convierten en protagonistas reales de los acontecimientos hasta el punto que determinan, 
en muchos aspectos y momentos, la visión y orientación de la sociedad. La imagen se vuelve familiar y educa la mirada (Freund, 2011), la vida política se hace común y sus imágenes estaban presentes en la vida diaria y familiar de la sociedad, para saltar de la oficialidad y convertirse en cotidiana. La fotografía como soporte de nuestra memoria trae al presente nuestro pasado al contener instantes reales de lo que acontecía en ese momento, recogiendo la espontaneidad de un periodo. España tiene un alto contenido en muestra fotográfica que sirve como base al historiador para los estudios sociales de evolución histórica, y también desde el punto de vista de la técnica.

En la mayoría de los casos, la construcción previa de la imagen mental, generada por la interacción de ideas, recuerdos o emociones, lleva al autor a crear un producto audiovisual, que tiene reminiscencias de otra creación que se relaciona de una manera intertextual (Villafañe, 2006).

Los autores que se han elegido para elaborar el análisis, presentados a continuación, lo han sido por la calidad y la importancia de su obra en el momento de su creación y su posterior difusión mundial. Aunque el trabajo que se ha elegido para el estudio metodológico no sea el más conocido dentro de su carrera, desde el punto de vista estético, histórico y cultural han tenido una importante difusión mediática, incluso a día de hoy, en exposiciones como Photoespaña 2008 en el caso de W. Eugene Smith, Exposición en la Casa Museo Cervantes en el caso de Ruth Matilda Anderson y las constantes revisiones que se publican sobre la vida y obra de Luis Buñuel. Todos ellos parten de un conocimiento previo de la zona, a través de escritos o de obras audiovisuales anteriores.

Comenzando por la autora norteamericana Ruth Matilda Anderson, importante en su época por la realización de numerosos reportajes de carácter antropológico y sociológico sobre diferentes puntos de la geografía española. De Luis Buñuel poco podemos añadir a la biografía, o al estudio de la obra del gran cineasta aragonés, se ha buscado la reinterpretación de la historiografía existente del autor a través de la obra elegida para el análisis. Y finalmente, Eugene Smith, al que dedicaremos un apartado especial y un análisis más detallado, no sólo de su obra de fotoensayo en general, sino a 
Spanish Village en particular. Todos ellos en un momento de su vida profesional tuvieron una vinculación extraordinaria con la tierra de Cáceres, punto de unión del estudio iconográfico de este trabajo.

Dentro de los estudios de estética, composición y audiovisuales se habla de la existencia de la "manipulación", o también se habla de la "construcción”. Es una característica que aparece indisolublemente ligada a la propia naturaleza de la fotografía. Si se tiene en cuenta una serie de cuestiones que se irán desgranando, debemos dar por sentado que la manipulación de la que hablaremos en la obra de Eugene Smith no está fuera de la ética, sino que más bien obedece a una estética aprendida y a un discurso visual que necesitaba de ciertos recursos estéticos para que las imágenes obtuviesen su categoría de informativas.

Uno de los problemas habituales en una investigación es descartar todo lo que no sea absolutamente necesario para el desarrollo de la misma, elementos que puedan distorsionar la lectura del texto visual, tales como pie de foto o textos explicativos de las mismas. En el caso de los objetos de estudio planteados, podernos ceñirnos a estudiar de forma particular una imagen, pero nunca podremos desposeerla de las circunstancias que la hicieron posible. Es lo que se ha dado en llamar Sociología Visual, siguiendo a los profesores Carmelo Pinto y J.M de Miguel. Si ahondamos en los documentos audiovisuales que han retratado la tierra de Extremadura, encontramos diferentes trabajos de los cuales, el más interesante, por su repercusión mediática y controversia, sería el de Spanish Village, realizado por Eugene Smith para la revista Life en 1950.

El mensaje visual no es una propuesta estética, sino la materialización de una simbiosis cultural que debe asimilarse e interpretarse en el contexto en que se implanta y desarrolla (Cañamero, 2012). El mensaje iconográfico se establece por influencia social, pretende persuadir, informar y remover conciencias con su diálogo, tanto si hablamos de una imagen fija, una fotografía, o como si nos referimos a una imagen en movimiento, el llamado cinematógrafo. 
No obstante, el campo histórico de actuación de la imagen o de los medios audiovisuales es bastante extenso y conviene acotar el período de estudio. De este modo, teniendo en cuenta los diversos cambios económicos, políticos, sociales y culturales que ha soportado España en las primeras décadas del S. XX la etapa de análisis y estudio se delimitan en los últimos años del reinado de Alfonso XIII, la II República y dos primeras décadas del franquismo, pues constituye un interesante momento por su contexto y complejidad.

Podemos poner nombre y apellido por fecha de presentación:

- Antecedentes:

- Mauricio Legendre, antecedente de los trabajos que se basarán en las Hurdes.

- Dr. Gregorio Marañón y el viaje que realizó el rey Alfonso XIII a la comarca de Las Hurdes.

- Ruth Matilda Anderson

- Luis Buñuel

- Eugene Smith

Estas circunstancias hacen que el objeto de estudio comience con el siglo XX, para centrarse en su parte final en el trabajo realizado por Eugene Smith en el año 1950 en España. Son los antecedentes visuales y documentales que en cierta medida pueden resultar similares a la imagen de pobreza y miedo que retrató el fotógrafo norteamericano para la revista Life.

\section{Imagen e intertextualidad}

La explicación y la comprensión del análisis del texto visual necesitan de un amplio marco teórico, histórico y estético. Esto ha hecho plantear el siguiente esquema de investigación que, aun pareciendo a priori amplio, se ha tenido que ajustar dejando al margen en muchos momentos del desarrollo del texto, aspectos, citas o nombres que tendrían cabida, pero que habrían hecho ampliar considerablemente el volumen de información. 
Aunque desde el punto de vista de la Historia de los Medios de comunicación, la imagen, en su concepto más amplio de fotografía y cinematógrafo, es relativamente reciente, la civilización de la imagen se instaura casi desde el mismo momento de su nacimiento. Hoy nuestro mundo está compuesto de imágenes, tenemos la sensación de que siempre ha sido así, pues la imagen se ha utilizado no sólo para ilustrar, sino también para educar, socializar, mostrar. Decía Walter Benjamín: "no el que ignore la escritura, sino el que ignore la fotografía será el analfabeto del futuro” (Benjamin, 2011).

La imagen es más que una simple representación icónica; es la congelación de un instante irrepetible. Es una de las mejores definiciones que podemos tener de imagen, en su forma de fotografía o cualquier otro producto audiovisual, y sin entrar en la polémica de si ese momento de la Historia es espontáneo o preparado.

Un fotógrafo que ha captado una imagen siempre buscará un fin. Está registrando una información, dejando de lado la representación icónica. Esta imagen nos informa de lo que el fotógrafo tenía delante en ese momento, su visión particular, bien sea objetiva o subjetiva.

Siguiendo la idea de Zavala (2003), podemos decir que la imagen es como un espejo donde se proyecta, se reconoce y se recrea la propia identidad a través del ejercicio de sensibilidad. Lo que se apuesta, la propia sensibilidad, la experiencia y la memoria, es decir, la identidad como visión del mundo, está determinada por un lapso de tiempo y por la atención que dedicamos al visionado de las imágenes.

"Toda imagen posee un referente en la realidad independientemente de cuál sea su grado de iconicidad, su naturaleza o el medio que la produce. Incluso las imágenes que surgen del nivel del imaginario, mantienen con la realidad nexos, que a veces son más sólidos de lo que una primera lectura hiciera suponer” (Villafañe, 2006, 30)

Así como de la credibilidad del autor firmante, que éste no tenga ninguna pátina de duda sobre su ética profesional, la imagen será admitida por la sociedad como una fiel reproducción de la realidad, donde no habrá 
cabida para la duda sobre la composición o manipulación de la estética de la fotografía (Minguez y Villafañe, 2006).

Los espectadores tanto de imagen fija, como en movimiento, esperan obtener algo valioso a cambio de su tiempo y su atención. Aunque lo más importante es la experiencia que va acumulándose en su memoria. Lo que hace cada uno de nosotros, a partir de esta experiencia personal, es generar expectativas particulares ante cada nueva experiencia audiovisual la acumulación de experiencias o la retención de información audiovisual en nuestra memoria: es un acto relativamente espontáneo. Reconstruimos después de una manera espontánea en nuestra imaginación los códigos que hemos ido almacenando (Sontag, 2003).

Para comprender el significado del término intertextualidad y su aplicación en el presente estudio, seguiremos la definición de Mijail Bajtin:

"Se entiende por intertextualidad, en sentido amplio, el conjunto de relaciones que acercan un texto determinado a otros textos de varia procedencia: del mismo autor o más comúnmente de otros, de la misma época o de épocas anteriores, con una referencia explícita (literal o alusiva, o no) o la apelación a un género, a un arquetipo textual o a una fórmula imprecisa o anónima”.

Siguiendo las referencias historiográficas, la definición y la acuñación del propio término "intertextualité” serían por parte de la autora Julia Kristeva:

"The transposition of one or more systems of signs into another, accompanied by a new articulation of the enunciative and a denotative position” (Prud'homme \& Légaré, 2006).

Hablando no de la influencia de unos autores en otros o de fuentes sino:

"Every text is constructed as a mosaic of citations; every text is an absorption and transformation of other text" (Prud'homme \& Légaré, 2006).

Trasladando la idea de intertextualidad literaria a la composición audiovisual, un autor sólo puede imitar lo que dijo/creó otro con anterioridad, y por tanto nunca puede ser original. El discurso que 
manifestamos bebe de discursos anteriores. La intertextualidad se convierte por tanto en una constante de la vida, no sólo de la creación artística.

Siendo puristas en extremo, antes de hablar de Kristeva como creadora o precursora de la intertextualidad, deberíamos remontarnos a F. Saussure, que descompuso el signo lingüístico en significante y significado, configurando las bases de los sistemas en los que descomponemos la comunicación. Bajtin, en sus trabajos, introduce el concepto de contexto social en las teorías de Sausurre. Kristeva, por su parte, lo lleva hasta su cénit, al introducir características sociales e históricas (Marinkovich y Benítez, 2004).

Barthes habla de la intertextualidad como "citas sin comillas" una construcción creativa a partir de nuestras experiencias previas, buscando en nuestra mente. En 1990 Hatim y Mason, nos dan un nuevo concepto de intertextualidad:

"The way we relate textual occurrences to each other and recognise them as signs as which evoke whole areas of previous textual experiences" (Marinkovich \& Benítez, 2004).

Los autores citados nos proponen diferentes categorías aplicables a las referencias de intertextualidad en textos y por ende, aplicables a la imagen al ser un signo reconocible, el texto icónico, por el hombre a nivel universal:

- Referencias: debe especificar el título, el capítulo... en el que aparece

- Cliché: expresión que llega a perder el significado con el paso del tiempo

- Alusión literaria: cita o referencia

- Cita propia

- Convencionalismo: frases que pierden su procedencia, y que de tanto repetirse se olvida la fuente de la que procede

- Proverbio: expresión que por su uso repetido ha llegado a ser memorable 
- Mediación: la plasmación en palabras de la experiencia hermenéutica de los efectos de un texto.

En nuestro estudio, los textos visuales tendrían cabida en la categoría de Cliché, teniendo en cuenta que también podrían ser aplicables los conceptos de Convencionalismo y Mediación. Y que tendremos que establecer mediante la aplicación de la metodología. Las alusiones harán referencia, mayoritariamente, a la tradición iconográfica occidental, la utilización de intertextos por parte de un autor puede ser algo inconsciente, o algo que obedezca a un fin concreto. Por lo tanto, no arbitrario, un acto consciente como homenaje o referencia a un autor u obra relevante para él.

El emisor lanza el intertexto en su obra, para que el receptor comprenda debe ser un intertexto compartido, un conocimiento compartido. Para poder entender el significado y la relación entre las imágenes o "textos visuales", debemos conocer los mecanismos del lenguaje empleado para ello, la semiótica. Lo podemos ver de forma explícita cuando se está haciendo una representación iconográfica ya establecida, como sería el caso de las madonas o en general, toda la simbología cristiana. En muchas ocasiones, puede ser algo menos explícito, simplemente alusivo, como en el caso que nos ocupa, donde la intertextualidad se ve definida no sólo por los elementos iconográficos, sino también por otros componentes del texto visual.

Las imágenes comienzan a formar parte de la cotidianeidad, independientemente de la nacionalidad de origen, gracias a la difusión de los Mass Media. Llega un momento en el cual reconocemos o conocemos una imagen sin tener claro de dónde proviene. Se recurre en muchas ocasiones a ellas por ser reconocibles, sacándolas del contexto para el cual fueron concebidos, la intertextualidad es una de las características de nuestra cultura iconográfica cristiana, la encontramos en casi todos los referentes reconocibles que nos rodean.

Muchos son los autores que hablan del fenómeno cultural que supone la intertextualidad, que salta del mundo del texto a la imagen. La relación entre fotografía e intertexto se pone de manifiesto en relaciones también textuales, 
aunque hablaríamos de "texto visual", pero que se pueden aplicar en la lectura y comprensión de imágenes, así hablaríamos de:

- Hipertetexto, la facultad de ver en un mismo texto de una forma diferente, realizando una lectura distinta que le da otro significado, como cuando una imagen se descontextualiza del reportaje o documento audiovisual para el que fue concebida.

- Paratexto, todo aquello que rodea al texto, o a la imagen, que nos da información adicional sobre el objeto iconográfico que es objeto de la lectura principal.

- Intertexto, un grupo de obras/imágenes que guardan relación entre sí, bien por hacer referencia a un icono común, bien por la relación explícita de los temas que tratan.

Referencia de intertextualidad sería la posibilidad de asociar un texto cualquiera, en el caso de la imagen también, con cualquier otro elemento o texto cultural. En esta intertextualidad, o más bien en su construcción, tenemos que barajar distintos elementos que interactúan, juntos o independientes entre sí.

La intertextualidad no es algo que dependa sólo y exclusivamente de la imagen que se estudia. La asociación intertextual que existe entre una imagen y su intertexto depende en gran medida del espectador. Quien observa la imagen o el texto descubre las relaciones que hacen posible la intertextualidad. Es una cuestión de perspectiva. En muchas ocasiones nace, como se ha señalado, o se señalará de una forma inconsciente por parte de la construcción de una imagen mental por parte del autor. Involucrando directamente al observador, como parte del proceso creativo, para que un intertexto sea significativo tiene que ser reconocido por el observador, formar parte también de su cultura iconográfica.

Situándonos en este contexto compositivo, el receptor no es un agente pasivo dentro del proceso comunicativo. Su condición social, su cultura e incluso su género, pueden condicionar la lectura que se hace de una imagen, interrelacionándola o no con su intertexto correspondiente. 
Algunos temas o estéticas dentro de la cultura occidental son recurrentes en la composición de imágenes: la tendencia a organizar los elementos compositivos de una imagen en grupos, por cercanía, semejanza...

De los ejemplos de imágenes que estudiamos, el hipertexto y el paratexto serían diferentes en cada caso. En el primer caso, nuestra interpretación del objeto iconográfico será distinta, dependiendo de nuestra sensibilidad o formación visual; en el caso del paratexto, la información que nos da es de espacio, no de tiempo, puesto que se ve desdibujado por las tomas realizadas en blanco y negro. En el caso del intertexto, la composición de las tres imágenes es similar, haciéndonos mirarlas de nuevo, e incluso planteándonos la posibilidad, en caso de no conocer los autores, de que sean obra de la misma mente creativa.

Para leer una imagen debemos tener en cuenta la interacción, fondo-figura. Distinguimos entre la figura principal y el fondo en el que se enmarca, pero cuando esta separación no es clara, el sistema perceptivo duda de la interpretación.

No nos encontramos imágenes sueltas, sin un texto o un pie de foto, o una serie de imágenes, fijas o en movimiento que ilustran una historia. Este texto o pie de foto se hace necesario algunas veces, pues esa imagen no perteneciente a una serie o a un reportaje necesita ser interpretada para el lector, en ocasiones esta leyenda, estas cuatro palabras las pone el redactor o el periodista, desvirtuando la esencia de la imagen.

\section{Explicación del método}

Se expone un análisis de la información obtenida, interpretándola mediante relaciones y argumentaciones que resulten coherentes con lo expuesto. Para ello se buscará el respaldo en un marco teórico fundamentado en disciplinas sociales, tales como la Sociología, la Psicología o la Historia.

Siguiendo a Javier Marzal, en su obra Cómo se lee una fotografía. Interpretaciones de una mirada, la ausencia de una metodología clara y específica para realizar sólo un análisis cualitativo y trasladarlo además al 
campo de las ideas, hace que se tenga que plantear la utilización de las disciplinas anteriormente citadas como base para la construcción del entramados metodológico y analítico de nuestra muestra (Marzal Felici, 2010).

Siguiendo las directrices que nos marca el autor mencionado anteriormente, el esquema de Laswell (Herrero, 2009, 59) es de gran utilidad para aplicarlo a los ejemplos iconográficos que se han seleccionado, puesto que tratamos la imagen, según hemos venido explicando, como un texto visual que para su comprensión necesita de la relación entre emisor y receptor.

El estudio de una imagen, que en este caso denominaremos "texto audiovisual”, se realizará mediante la aproximación a su contexto sociológico, histórico y cultural. Puesto que se ha determinado que la metodología aplicada está basada en un análisis cualitativo, el contexto en el que se desarrolla el texto audiovisual tendrá más peso específico, que el canal comunicativo, puesto que éste hace más hincapié en la parte correspondiente a la tecnología aplicada para la obtención de dichas imágenes, puesto que el texto visual requerido para la muestra sólo requiere de una característica tecnológica común, ser imágenes no tratadas o recogidas por medios digitales.

Conocer la personalidad del "Emisor", del autor del trabajo, no es sólo una necesidad para determinar su evolución artística, sino también un referente a la hora de entender la posterior obra de los autores, también la muestra que se ha seleccionado para el análisis dentro de sus características y condicionantes contextuales. Siempre teniendo en cuenta que las biografías, o apuntes biográficos, que se puedan leer y mostrar en este estudio están “contaminados”, puesto que si son escritos por terceros contarán con el sesgo informativo, y si son autobiográficos se pondrá de manifiesto la subjetividad del autor a la hora de determinar las cuestiones que tienen mayor relevancia. Si es una autobiografía, nos encontraremos ante el mismo problema, el autor/artista hace un balance de su vida por escrito poniendo "énfasis" en los hechos que para él han sido relevantes tanto a nivel personal como creativo, positivos o negativos, lo que supondrá también un sesgo informativo 
importante. Es una perspectiva que hay que tener en cuenta: la intencionalidad del autor dependiendo de la referencia que se haya elegido para elaborar la biografía.

En los primeros años de existencia de la imagen fija, y posteriormente de la imagen en movimiento, el estudio del texto audiovisual no puede disociarse del análisis de la técnica y de las influencias artísticas provenientes de la pintura en el primer caso y del teatro en el segundo, pero puesto que el estudio de caso que nos ocupa está situado a partir de la segunda década del siglo XX, estas primitivas influencias han ido desapareciendo en gran medida. Aunque se siga con rigor la metodología planteada y se busque una justificación teórica en todas aquellas afirmaciones que se planteen. El eminente carácter "subjetivo" que subyace en todas las investigaciones históricas, al no poder tener un testimonio de primera mano de los protagonistas, estará latente sobre todo cuándo se describan las directrices del contexto histórico en el que se desenvuelven los autores, y por tanto sus obras creativas al venir ligados con unas décadas especialmente convulsas en la historia del siglo XX, donde la cultura, al igual que ha sucedido en otras épocas de la humanidad, va a sufrir la interacción de factores externos como serán el estadio o las Guerras Mundiales.

La cultura, o lo que es entendido por contexto cultural, esos factores que rodean el desarrollo creativo de los movimientos artísticos, las podemos describir como un estado o hábito mental que puede convertirse en una forma de vida íntimamente vinculada a los retos y dilemas de la sociedad, en este caso concreto de la Sociedad Contemporánea.

Sobre el método histórico en fotografía, Beaumont Newhall en 1937, en su Historia de la Fotografía, aplica la forma tradicional de la Historiografía del Arte. Agrupa la producción de los fotógrafos por escuelas o estilos, lo mismo que se hace con la división del cine en géneros. De ahí que la muestra elegida sean imágenes que manifiestan una directriz común, son imágenes “documentales reales" de una sociedad determinada, puesto que se integran dentro de la corriente considerada documental. 
Dando un paso más, tendríamos la metodología de Lemagny y Rouillé, que también une las imágenes con los campos del arte y la cultura de un país. Analiza periodos específicos, algo que se intentará aplicar también a lo largo del análisis que se planteará más adelante. La elección de estos autores se debe a que reflejan un interés en su vida y en su obra para los campos de las Humanidades, tales como la Historia o la Sociología, lo que se adecua a la intencionalidad inicial de este estudio.

Uno de los referentes no sólo históricos sino también fotográficos, Giséle Freund, en su trabajo La fotografía como documento social, publicado por primera vez en 1974 apuntaba:

"El gusto no es una manifestación inexplicable de la naturaleza, humana, sino que se forma en función de unas condiciones de vida muy definidas que caracterizan la estructura social en cada etapa de su evolución..." (Freund, 2011)

Lo que nos viene a confirmar nuestra idea de trabajo que la composición de una imagen, su intertextualidad viene dada en muchas ocasiones, y en gran medida, por nuestra cultura o tradición iconográfica.

Cabe citar dentro de los autores que nos muestran la relación entre Sociología y fotografía, Carmelo Pinto y J.M. de Miguel en Sociología Visual (De Miguel y Pinto, 2002), una obra que nos acerca a lo que era Deleitosa, un ejemplo de la Extremadura de la época, uno de los objetos de este estudio en la década de los cincuenta y su evolución hasta las fechas actuales, ayudándonos así con la fotografía a comprender la cultura de Extremadura, dándonos una fuente de representación de los tipos humanos y aproximándonos a un estudio antropológico.

Desde el punto de vista de la perspectiva tecnológica, para poder atender a este apartado, utilizaremos el esquema Laswell, para comprender la necesidad de un lenguaje común entre el emisor y el receptor.

De los tres grupos de imágenes que se han elegido como muestra para el estudio, se debe tener en cuenta que la fuente de la que provienen son:

- Formatos: Cinematógrafo y Fotografía 
- Tiempo: provienen de décadas diferentes, lo que también condiciona la técnica aplicada.

- Finalidad: las imágenes obtenidas tendrán distinta finalidad, una exposición documental, exhibición cinematográfica y un ensayo fotográfico para prensa escrita.

La definición de técnica más adecuada al enfoque dado al presente estudio sería: "Método y procedimiento práctico (incluido sus medios) para obtener una obra y sus resultados", mientras que la tecnología: "el estudio de la técnica como elemento de la cultura” (Gutierrez Espada, 1991, 23).

Este hándicap tecnológico hace que el estudio desde este mismo punto de vista no sea absolutamente determinante a la hora de hablar del tema propuesto, la intertextualidad, pues tanto el método de captura como la finalidad de la imagen obtenida no tienen un hilo conductor o una finalidad común.

Desde el punto de vista de la composición argumental, podemos encontrar paralelismos entre las diferentes obras escritas, audiovisuales y gráficas, de algunos autores que se detallan a continuación, no por ello siendo las únicas en las que podemos encontrar dichas referencias iconográficas:

- Mauricio Legendre, Las Jurdes. Étude de géographie humaine, 1927

- Ruth Matilda Anderson

- Revistas impresas que detallan la primera visita de Alfonso XIII a las Hurdes

- Segunda visita de Alfonso XIII a las Hurdes, narrada de igual modo

- Documental Las Hurdes: Tierra sin Pan, de Buñuel

- Gerald Brenand por España

- Eugene Smith

- Josip Ciganovic 
En el plano compositivo, estas imágenes no son únicas y exclusivas de nuestro país. En las décadas de los 30, 40 y 50, han dejado buena muestra de este tipo de imágenes por todo el mundo:

- Farm Security Administration

- Henri Cartier-Bresson

- Marc Riboud

\section{Grupos de muestra}

Según hemos visto, se ha elegido una muestra de imágenes que corresponde a los trabajos de los autores presentados, que se ciñen a los grupos de análisis que se plantean, y que muestran el desarrollo iconográfico y social, que manifiestan los paralelismos visuales, y que tradicionalmente se encuentran en los géneros audiovisuales presentados, son: vivienda, infraestructuras, maternidad e infancia.

Puesto que la inclusión de las plantillas supondría una extensión excesiva, hemos elegido presentar la reflexión general de las imágenes en su conjunto.

- Vivienda

El motivo iconográfico es común, imágenes costumbristas, arquitecturas toscas de adobe y pizarra situadas en el último plano, anteponiendo figuras humanas. Las líneas vienen dadas por las construcciones. Todas ellas parecen no ser fruto de la casualidad, mostrando una preparación que equilibra la escena. Las relaciones intertextuales en esta secuencia de imágenes se establecen no sólo por los elementos compositivos sino también por su carga simbólica de representación, mostrando la sencillez de la vida sin que parezca evolucionar en 30 años- reflejando la sencillez de vida de las gentes extremeñas, con un motivo iconográfico común que recuerdan las imágenes "costumbristas".

- Infraestructuras 
Las estrategias de creación o re-escenificación de "paisajes vivientes” son algo habitual en las representaciones iconográficas. La composición en este grupo de imágenes mediante la construcción o reconstrucción de las escenas es un rasgo común. La intertextualidad viene dada por uno de los elementos iconográficos, no por la imagen en conjunto, el agua, rodeada de personajes secundarios, pero que la erigen como protagonista al ser un bien necesario para la existencia. Aunque es un elemento que se convierte en una excusa para introducir otros elementos que nos conmueven y que se analizan a continuación, las mujeres y los niños.

- Maternidad

La fotografía y el cine son herederos iconográficos de las artes anteriores utilizando la imagen femenina como icono en toda su extensión. Aunque en este grupo de análisis, la representación que adoptan es la de la maternidad, una mujer con un pequeño en brazos como centro de sus composiciones artísticas. El sentimiento de empatía y la comprensión del texto visual que se podrían despertar con el receptor serían inmediatos, dejando patentes relaciones intertextuales, no sólo entre la muestra presentada, si no con las representaciones iconográficas de nuestra tradición cristiana.

- Infancia

Las imágenes que representan gente con apariencia de pobreza suelen llamar la atención, más en el caso que nos ocupa en este punto, cuando son niños, un recurso utilizado frecuentemente en imágenes fijas o en movimiento. Si bien la apariencia compositiva puede no dar un primer punto de conexión, la intertextualidad viene dada no sólo por el objeto iconográfico, los niños, sino por la percepción y la sensación, el universo de los sentimientos que se despiertan ante la infancia.

\section{Conclusiones}

No podremos conocer las verdaderas intenciones de Ruth Matilda Anderson, Luis Buñuel o Eugene Smith más que ellos mismos. Los receptores a la hora 
de realizar el estudio nos sentimos cautivados por sus imágenes y podemos lanzar hipótesis, recogiendo a su vez el testigo de otros que antes que nosotros buscaron también entender las motivaciones que regían la realización de sus trabajos fotográficos, en los que encontramos la impronta de los genios. Sin embargo, y a pesar de las diferencias de estilo, comparten en sus trabajos un mensaje y un tema central, lo que hace que se interrelacionen y se sucedan en el tiempo, como un referente visual del estancamiento evolutivo de una sociedad concreta.

El emisor lanza el intertexto, para que el receptor comprenda debe ser un intertexto compartido, para poder entender el significado y la relación entre las imágenes o “textos visuales”. La imagen es más que una simple representación icónica: es la congelación de un instante irrepetible, es una de las mejores definiciones que podemos tener de imagen, en su forma de fotografía o cualquier otro producto audiovisual. Las imágenes nos hablan, nos muestran aspectos de otra persona o lugares, vivienda, infraestructura, maternidad e infancia. Con el paso del tiempo y la repetición del objeto iconográfico, se convierte en algo que forma parte de nuestra vida o memoria, construyendo un icono fácilmente reconocible, una figura maternal es fácilmente reconocible, incluso descontextulizada, en el caso que nos ocupa la visión de una mujer sosteniendo a un bebé en brazos representa el intertexto. Su fuerza reside en el intertexto y en la representación iconográfica, el significado figurativo de la misma, independiente de la técnica empleada o el tiempo transcurrido desde su creación.

La imagen construida declara, desde el principio, que ha sido realizada por un creador de imágenes. La subjetividad se pone de manifiesto en las tomas recogidas para el análisis que van reflejando, sobre todo en el caso de Luis Buñuel y Eugene Smith, la plasmación de la imagen mental. La creación e interpretación de lo percibido sobre la tierra y las gentes, unido a un conocimiento previo de los tipos, la geografía, los paisajes hacen que, incluso descontextualizando, el "texto visual” pueda ser leído incluso más de medio siglo después de su difusión. 
Las estrategias de creación y/o re-escenificación de “paisajes vivientes" se reflejan en el modo en que los autores estructuraron sus trabajos, mostrando una intencionalidad documental, la "construcción" o "puesta en escena” para recrear la idea que quieren transmitir, convirtiéndola en un mensaje entendible para el receptor, partiendo en todas las imágenes presentadas de una base real, hace que la "manipulación" de la que podríamos acusar a los autores, sería únicamente de esa recreación o reconstrucción de un momento que no pudo ser capturado como "instante decisivo" y que se reproduce con los protagonistas del mismo.

La intertextualidad no es algo que dependa sólo y exclusivamente de la imagen que se estudia, la relación intertextual que existe entre una imagen y su intertexto depende en gran medida del espectador, es el fruto de la mirada del observador, más que de la intencionalidad primaria del autor, es una cuestión de percepción de perspectiva, que nace de manera inconsciente.

La imagen es uno de los mejores soportes que hay para la memoria. Nos trae al presente retazos del pasado o nos lleva a un lugar que nunca hemos visitado mostrándonos rostros de personas desconocidas que invitamos a entrar en nuestros hogares. Nos permite conservar fragmentos del pasado, imágenes que no volverán a repetirse, y que incluso, han desaparecido. Y gracias a ella, no las olvidaremos, conservándolas todo el tiempo que la técnica nos permita.

\section{Referencias bibliográficas}

Benjamin, W. (2011). Breve Historia de la Fotografía. Madrid: Casimiro Libros.

Cañamero, M. C. (2012). Intertextualidad Audiovisual condicionada por la imagen mental: Extremadura a través de Anderson, Buñuel y Smith. (Tesis doctoral inédita). Madrid: Universidad CJC.

De Miguel, J. M., \& Pinto, C. (2002). Sociología Visual. Madrid: CIS, \& S. XXI, Edits.

Fontcuberta, J. (1984). El Beso de Judas. Barcelona: Gustavo Gili.

Freund, G. (2011). La fotografía como documento social. Barcelona: Gustavo Gili. 
Gutierrez Espada, L. (1991). La función social de la Imagen Audiovisual. Madrid: UCM.

Herrero, J. C. (2009). Manual de Teoría de la Información y de la Comunicación. Madrid: J. C. Herrero Ed.

Marinkovich, J., \& Benítez, R. (2004). Aproximaciones al análisis intertextual del discurso científico. Revista signos, 33 (48), 117-128.

Marzal Felici, J. (2010). Cómo se lee una fotografía. Interpretaciones de una mirada. Madrid: Cátedra.

Minguez, N., \& Villafañe, J. (2006). Principios de Teoría General de la Imagen. Madrid: Pirámide.

Prud'homme, J., \& Légaré, L. (2006). A Semiology of Paragrams. Recuperado el 04 de 08 de 2010, de http://www.signosemio.com/kristeva/semiology-of-paragrams.asp

$R A E$. (s.f.). Recuperado el 01 de 03 de 2010, de Real Academia Española: http://buscon.rae.es

Sontag, S. (2003). Ante el dolor de los demás. Madrid: Alfaguara.

Villafañe, J. (2006). Introducción a la teoría de la Imagen. Madrid: Pirámide.

Zavala, L. (2003). Elementos del discurso cinematográfico. Unidad Xochimilco: Universidad Autónoma Metropolitana. 